\title{
Abnormal Downregulation of Caveolin-3 Mediates the Pro-Fibrotic Action of MicroRNA-22 in a Model of Myocardial Infarction
}

\author{
Lu Zhang ${ }^{a}$ Hongli Yina Lei Jiao ${ }^{a}$ Tianyi Liua,b Yuqiu Gao ${ }^{a} \quad$ Yingchun Shao $^{a}$ \\ Yuanyuan Zhang ${ }^{a} \quad$ Hongli Shan $^{a}$ Ying Zhang $^{a}$ Baofeng Yang ${ }^{a, c}$ \\ aDepartment of Pharmacology (State-Province Key Laboratories of Biomedicine- Pharmaceutics \\ of China, Key Laboratory of Cardiovascular Medicine Research, Ministry of Education), College of \\ Pharmacy, Harbin Medical University, Harbin, Heilongjiang, 'bepartment of Pharmaceutics, Dalian \\ Children's Hospital, Dalian, Liaoning, China, 'Department of Pharmacology and Therapeutics, \\ Melbourne School of Biomedical Sciences, Faculty of Medicine, Dentistry and Health Sciences, \\ University of Melbourne, Melbourne, Australia
}

\author{
Key Words \\ Myocardial infarction - Ceveolin - MicroRNAs
}

\begin{abstract}
Background/Aims: Cardiac fibrosis is an important cardiac remodeling event that can ultimately lead to the development of severe arrhythmia and heart failure. MicroRNAs (miRNAs) are involved in the pathogenesis of many cardiovascular diseases. Here, we aimed to investigate the effects of caveolin-3 (Cav3) on the pathogenesis of cardiac fibrosis and the underlying molecular mechanisms. Methods: Cav3 expression was decreased in cardiac fibrosis in vivo and in vitro model. To investigate the role of Cav3 in cardiac fibrosis, we transfected cardiac fibroblasts (CFs) with the siRNA of Cav3 and Cav3-overexpressing plasmid. The collagen content and proliferation of CFs were detected by QRT-PCR, western blot, MTT, and immunofluorescence. A luciferase reporter gene assay and gain/loss of function were used to detect the relationship between miR-22 and Cav3. Results: Cav3 depletion in CFs induced an increase in collagen content, cell proliferation, and phenotypic conversion of fibroblasts to myofibroblasts. Conversely, Cav3 overexpression in CFs was shown to inhibit angiotensin II-mediated excessive collagen deposition through protein kinase $\mathrm{C}(\mathrm{PKC}) \varepsilon$ inactivation. Cav3 was experimentally confirmed as a direct target of miR-22, containing two seed binding sites in its $3^{\prime}$-untranslated region, and miR-22 was demonstrated to be significantly upregulated in the ischemic border zone in mice after myocardial infarction and in neonatal rat CFs pretreated with angiotensin II. miR-22 overexpression increased CFs proliferation, and collagen and $\alpha$-smooth muscle actin levels in CFs, while the knockdown of endogenous miR-22 decreased
\end{abstract}

L. Zhang, H. Yin and L. Jiao contributed equally to this work.

Ying Zhang

and Baofeng Yang

KARGER
Department of Pharmacology, Harbin Medical University

Baojian Road 157, Harbin, Heilongjiang Province (P. R. China)

E-Mail jennying223@126.com, yangbf@ems.hrbmu.edu.cn 
CFs numbers. Conclusions: Our findings demonstrate that miR-22 accelerates cardiac fibrosis through the miR-22-Cav3-PKC $\varepsilon$ pathway, which, therefore, may represent a new therapeutic target for treatment of excessive fibrosis-associated cardiac diseases.

(C) 2018 The Author(s)

Published by S. Karger AG, Basel

\section{Introduction}

Cardiac fibrosis is a structural remodeling process commonly observed in various cardiovascular diseases, such as hypertension, coronary heart disease, and heart failure [1-3]. This process can be triggered by many pathological conditions including myocardial ischemia/infarction (MI), cardiac overload, hypoxia, and others. In MI, the reduction of blood supply, carrying oxygen and nutrients, results in metabolic disturbances accompanied by a massive cardiomyocyte loss that surpasses the limited regenerative capacity of myocardium, leading to the formation of a fibrotic scar replacing the damaged tissue [4]. In the early stage of MI, synthesis and deposition of extracellular matrix (ECM) can induce local contractility and improve heart function. However, in the later stage, excessive ECM deposition can lead to cardiac fibrosis, and ultimately to cardiac dysfunction [5, 6]. Cardiac fibrosis is characterized by the excessive deposition of ECM components, including collagen type I and III, and the proliferation and phenotypic conversion of fibroblasts [7, 8]. Ultimately, the excessive deposition of ECM can result in heart dilation and failure [9-11].

Caveolae, small invaginations of cell membrane, represent a unique form of lipid rafts commonly found in the cardiovascular system, which are actively involved in many physiological processes $[12,13]$. Caveolins are the main protein components of caveolae, and this family includes caveolin-1, caveolin-2, and caveolin-3 (Cav3) [14, 15]. Of these, Cav3 is the most important caveolin found in heart, composed of 151 amino acids, while its transmembrane domain consist of 33 amino acids [16]. Cav3 is involved in signal transduction both inside and outside of the myocardial cell membrane, and its defects are closely associated with heart disease development. Previous studies reported that Cav3 contributes to a variety of cardiac pathophysiological processes such as arrhythmogenesis, myocardial hypertrophy, and myocardial ischemia/reperfusion injury [17-19]. Cav3 was shown to be associated with protein kinase C (PKC) signaling, known to induce fibrogenesis [20-22]. PKC belongs to a family of Ser/Thr protein kinases, commonly expressed in eukaryotic cells, and several subtypes have been identified, including PKC $\alpha, \mathrm{PKC} \beta, \mathrm{PKC} \delta$, and PKC $[23]$. $\mathrm{PKC} \varepsilon, \mathrm{PKC} \delta$, and $\mathrm{PKC} \alpha$ were shown to be able to couple with the caveolin-enriched plasma membrane microdomain of cardiac myocytes, and PKC $\varepsilon$ can directly interact with Cav3 [24, 25]. In response to environmental cues such as hypoxia and the increase in angiotensin II (AngII) levels, PKC can induce the translocation of Cav3 to cell membrane and the coupling between PKC and Cav3 is enhanced [18, 25, 26, 27]. The activation of PKC $\varepsilon$ was shown to promote the proliferation of cardiac fibroblasts and induces cardiac fibrosis [22], indicating the potential role of Cav3 in fibrogenesis in heart. However, no previous studies examined the role of Cav3 in the regulation of cardiac fibrosis.

MicroRNAs (miRNAs) are a class of small RNAs, generally approximately 21 to 25 nucleotides long, which bind to the seed sequences in the $3^{\prime}$ untranslated region (3'-UTR) of the target genes and inhibit gene expression at the post-transcriptional level [28]. miRNAs are generally found in multicellular organisms and are numerous, accounting for about $2 \%$ of the total genome $[29,30]$. They are highly evolutionary conserved and are involved in the development of many cardiovascular diseases [31], such as arrhythmia, cardiac hypertrophy, heart failure, MI, and others. Previous studies demonstrated that miRNAs can regulate the synthesis and metabolism of ECM in the heart. For example, miR-1, miR-24, miR-29, miR-30, and miR-133a were shown to promote fibrosis through the regulation of collagen synthesis by cardiac fibroblasts [32-42]. miR-21 and miR-208a can inhibit cardiac fibrosis by regulating relevant genes in the fibrotic signaling pathways [43-47]. Our pilot study, performed using TargetScan miRNA databases, demonstrated that Cav3 may represent a potential target of miR-22. 


\section{Cellular Physiology Cell Physiol Biochem 2018;45:1641-1653 \begin{tabular}{ll|l} 
and Biochemistry & $\begin{array}{l}\text { DOI: 10.1159/000487732 } \\
\text { Published online: February 26, } 2018\end{array}$ & $\begin{array}{l}\text { C } 2018 \text { The Author(s). Published by S. Karger AG, Basel } \\
\text { www.karger.com/cpb }\end{array}$ \\
\hline
\end{tabular} \\ Zhang et al.: Mir-22: A Cardiac Fibrosis Activator}

Here, we hypothesized that Cav3 regulates cardiac fibrosis, PKC $\varepsilon$ at least partially mediates the fibrosis-regulating property of Cav3, and that miR-22 controls Cav3 cellular levels.

\section{Materials and Methods}

\section{Mouse model of MI}

Male Kunming mice (weighing 20 25 g) underwent the ligation of the left descending anterior coronary artery (LAD) to establish the MI model [48]. All experiments were performed according to the guiding principles of Laboratory and Animal Care Committee of the Harbin Medical University (Harbin, China). Four weeks after the ligation, hearts were rapidly removed and prepared for Masson staining or other experimental interventions. All protocols were performed in accordance with the Guide for the Care and Use of Laboratory Animals, published by the US National Institutes of Health (NIH Publication No.85-23, revised 1996).

\section{Rat cardiac fibroblast culture and the cellular model of cardiac fibrosis}

Cardiac fibroblasts were isolated from the neonatal Sprague-Dawley rats (1 3 days old), as previously described [49]. The cells were cultured in Dulbecco's Modified Eagle Medium (DMEM; Biological Industries, Kibbutz BeitHaemek, Israel) with 10\% fetal bovine serum (FBS; Biological Industries) and incubated at $37^{\circ} \mathrm{C}$ in the humidified atmosphere with $5 \% \mathrm{CO}_{2}$. After $48 \mathrm{~h}$, second and third passage cardiac fibroblasts were incubated in the serum-free DMEM for $4 \mathrm{~h}$, which was followed by the addition of AngII (100 nM), and additional incubation for $48 \mathrm{~h}$ to stimulate cardiac fibrogenesis.

\section{qRT-PCR}

Total RNA was isolated from cardiac fibroblasts using Trizol reagent (Invitrogen, Carlsbad, USA) according to the manufacturer's protocols. Total RNA $(1 \mu \mathrm{g})$ was used for synthesizing first-strand cDNA using cDNA Reverse Transcription Kit (Applied Biosystems, Foster City, USA). qRT-PCR was performed with SYBR Green Mix kit (Applied Biosystems) according to the manufacturer's instructions. The relative RNA levels were calculated using the ${ }^{\triangle A} \mathrm{Ct}$ method. GAPDH levels served as an internal control. miR-22 expression was assessed using the qRT-PCR miRNA Detection Kit (Applied Biosystems), with U6 levels as an internal control. The primer sequences used for the amplification are shown in Table 1.

\section{Transfection procedures}

Cardiac fibroblasts were seeded in six-well plates. After serum-starving the cells for $4 \mathrm{~h}$, miR-22 (Gene Pharma, Shanghai, China) and Cav3 siRNA (siCav3; Gene Pharma, Shanghai, China) were transfected into the cardiac fibroblasts using X-treme, according to the manufacturer's instructions (Roche Molecular Biochemicals, Basel, Switzerland). The transfection efficiency was measured by qRT-PCR. The sequences we tansfected were as follows: miR-22, sense: ${ }^{\prime}$-AAGCUGCCAGUUGAAGAACUGU-3' and antisense: 5'-AGUUCUUCAACUGGCAGCUUUU-3'; AMO-22: $5^{\prime}$ - A C A G U U C U U C A A C U G GCAGCUU-3'; NC(for miRNA), sense: $\quad 5^{\prime}$-UUCUUCGAACGUGUCACGUTT- $3^{\prime}$ and antisense: $5^{\prime}$ - ACGUGACACGUUCGGAGAATT-3'; siCav3, sense: 5'-GCAGCAACAUUAAGGUGGUTT- $3^{\prime}$ and antisense: $5^{\prime}$-ACCACCUUAAUGUUGCUGCTT-3'; NC (for SIRNA), sense: $\quad 5^{\prime}$-UUCUUCGAACGUGUCACGUTT- $3^{\prime}$ and antisense: $5^{\prime}$-ACGUGACACGUUCGGAGAATT- $3^{\prime}$.

Table 1. Gene-specific primers for real-time PCR

\begin{tabular}{lllll}
\hline Gene name & Accession number & Forward primer $\left(5^{\prime}\right.$-3') & Reverse primer (5'-3') & Product size \\
\hline CAV-3 (rat) & NM_019155 & GTGGACTGAGGGCAGGTGA & GTGTTTCCCGCTCCGTGT & $105 \mathrm{bp}$ \\
Col1a1 (rat) & NM_053304 & TCAAGATGGTGGCCGTTACT & CATCTTGAGGTCACGGCATG & 166bp \\
Col3a1 (rat) & NM_032085 & TGGGATGCAACTACCTTGGT & AGGTGTAGAAGGCTGTGGAC & 194bp \\
Mmp9 (rat) & NM_031055 & CCACCGAGCTATCCACTCAT & GGTCCGGTTTCAGCATGTTT & 160bp \\
CAV-3 (mouse) & NM_007617 & TCAACGATACCAGCCACAAG & ACACCGTCGAAGCTGTAGGT & $226 \mathrm{bp}$ \\
Col1a1 (mouse) & NM_007742 & GAGCGGAGAGTACTGGATCG & TACTCGAACGGGAATCCATC & $204 \mathrm{bp}$ \\
Col3a1 (mouse) & NM_009930 & GTTGTGCAATATGCCCACAG & CCTCCCACTCCAGACTTGAC & $246 \mathrm{bp}$ \\
GAPDH & NM_017008 & TCTACATGTTCCAGTATGACTC & ACTCCACGACATACTCAGCACC & 162bp \\
miR-22 (rat) & NR_031824 & AAGCTGCCAGTTGAAG & CAGTGCGTGTCGTGGAGT & 281bp \\
U6 (rat) & NM_001126085 & GCCTGGATGGCTACATGAAT & ATCCATCGCTGAAGAGCAGT & 175bp \\
\hline
\end{tabular}




\section{Cellular Physiology Cell Physiol Biochem 2018;45:1641-1653 \begin{tabular}{l|l|l} 
and Biochemistry 10.1159/000487732 & $\begin{array}{l}\text { C } 2018 \text { The Author(s). Published by S. Karger AG, Basel } \\
\text { www.karger.com/cpb }\end{array}$ \\
\hline
\end{tabular}}

Zhang et al.: Mir-22: A Cardiac Fibrosis Activator

\section{Western blotting}

Total proteins were extracted from cardiac fibroblasts. After transfection or other treatments, the cells were lysed with $20 \mu \mathrm{L}$ of RIPA Buffer (Roche Molecular Biochemicals, Basel, Switzerland), and protein concentrations were detected using BCA kit (Beyotime, Shanghai, China), according to the manufacturer's guidelines. Protein samples $(20 \sim 40 \mu \mathrm{g})$ were separated on a SDS-PAGE gels, and transferred to nitrocellulose membranes. After blocking the membranes with 5\% skim milk in phosphate-buffered saline (PBS) for $1 \mathrm{~h}$ at room temperature, the membranes were probed with anti-Cav3 (Santa Cruz Biotechnology, California, USA), anti- $\alpha$-SMA (Abcam, Cambridge, USA), anti-PKC $\varepsilon$ (PeproTech, New Jersey, USA), anti-pPKC $\varepsilon$ (Santa Cruz Biotechnology, California, USA), and anti- $\beta$-actin (Zhongshanjinqiao, Beijing, China) antibodies at $4^{\circ} \mathrm{C}$ overnight. The nitrocellulose membranes were washed with PBST (PBS containing 0.5\% Tween 20) three times for $7 \mathrm{~min}$ each, which was followed by the incubation with a fluorescence-labelled secondary antibody (IRDye700/800 mouse and rabbit antibodies) (Santa Cruz Biotechnology, California, USA). Protein levels were determined using Odyssey infrared scanning system (LI-COR Biosciences, Lincoln, USA) and the band intensities were quantified using Image J software.

\section{Masson trichrome staining}

The hearts of MI mice were rapidly removed after sacrifice, and the infarct border zone was carefully dissected and immediately immersed in 4\% neutral buffered formalin for $24 \mathrm{~h}$. Afterwards, paraffinembedded slices were stained with Masson trichrome stain. Collagen fibers were stained blue and cardiac tissue morphological changes were examined under a light microscope.

\section{Luciferase reporter assay}

For the luciferase assay, the luciferase reporter plasmids, together with $20 \mu \mathrm{mol} / \mathrm{L}$ of miR-22, AM0-22, or NC miRNA, and $0.5 \mu \mathrm{g}$ psi-CHECK2 target DNA were transfected into HK293T cells (seeded at 50 60\% confluence). Following $48 \mathrm{~h}$ incubation, luciferase activity was detected using the Dual luciferase reporter assay kit (Promega, Wisconsin, USA) on a luminometer (Promega E5331), according to the manufacturer's specification. Base-pair substitutions of mutations were performed using direct oligomer synthesis for the miR-22 bindings sites in the 3'-UTR of the Cav3 gene. All constructs were confirmed by sequencing.

\section{Immunofluorescence staining}

Cultured rat cardiac fibroblasts attached to aseptic glass coverslips were washed with PBS five times and fixed in 4\% paraformaldehyde for 15 min. Afterwards, the cells were incubated with Triton X-100 at $37^{\circ} \mathrm{C}$ for 20 min to allow membrane penetration, and this was followed by three washes with PBS and incubation with goat serum (blocking solution) at $37^{\circ} \mathrm{C}$ for $30 \mathrm{~min}$. The samples were then incubated with a diluted anti- $\alpha$-SMA antibody (Abcam) at $4^{\circ} \mathrm{C}$ overnight, followed by the incubation with FITC-conjugated goat anti-rabbit antibody for 90 min. DAPI (Roche Molecular Biochemicals) was used to stain cell nuclei. Immunofluorescence staining was examined under a confocal laser microscope (Olympus, Tokyo, Japan).

\section{Cell viability assay}

Cell viability was measured by MTT assay. Cardiac fibroblasts were seeded in the 96-well plates at a density of $5 \times 10^{3} /$ well. After $48 \mathrm{~h}$, cardiac fibroblasts were incubated in the serum-free DMEM for $4 \mathrm{~h}$. AngII or transfection reagent was added to the cells. Forty-eight hours after incubation, cardiac fibroblasts were treated with $5 \mathrm{mg} / \mathrm{mL}$ MTT (20 $\mathrm{LL} /$ well) for $4 \mathrm{~h}$. After DMEM was carefully removed, DMSO (200 $\mu \mathrm{L} /$ well) was added, followed by 15-min shaking. The absorbance was measured at $570 \mathrm{~nm}$ using an Infinite $200 \mathrm{PRO}$ microplate spectrophotometer (Tecan, Salzburg, Austria), and each measurement was obtained in triplicate. Relative absorbance values (normalized to the control) were used as an indication of cell viability.

\section{Transfection of cells with Cav3 plasmid}

Neonatal rat cardiac fibroblasts were seeded in six-well culture plates. After serum-starving the cells for $4 \mathrm{~h}$, cardiac fibroblasts were transfected with the Cav3-overexpressing plasmids, and this gene was transiently overexpressed using the X-treme GENE siRNA Transfection Reagent (Roche Molecular Biochemicals), according to the manufacturer's protocol. Following the different treatments, total RNA and protein samples were extracted from the cells for qRT-PCR and western blot analysis. 


\section{Cellular Physiology Cell Physiol Biochem 2018;45:1641-1653 \begin{tabular}{l|l|l|l|l} 
DOI: 10.1159/000487732 2018 The Author(s). Published by S. Karger AG, Basel & and Biochemistry \\
Published online: February 26, 2018 & www.karger.com/cpb
\end{tabular} \\ Zhang et al.: Mir-22: A Cardiac Fibrosis Activator}

Statistics

Quantitative data were reported as mean values \pm standard error of mean (SEM), and differences between groups were compared using one-way analysis of variance (ANOVA). P $<0.05$ was considered statistically significant.

\section{Results}

Cav3 expression is downregulated in ischemic myocardia and AngII-treated cardiac fibroblasts

Masson staining results showed the development of cardiac fibrosis, with the considerable deposition of collagen in the myocardia of MI mice but not in the Sham group (Fig. 1a). Western blot results showed that $\alpha$-smooth muscle actin ( $\alpha$-SMA) levels were increased in the MI hearts compared with those in the Sham group (Fig. 1b). The expression of Cav3 at both mRNA and protein levels in the border zone of the infarcted myocardia was shown to be considerably lower in the MI mice, compared with that in the same region of the Sham group hearts (Fig. 1c and 1d).

In the cultured neonatal cardiac fibroblasts, AngII (100 nM) treatment induced the increase in the mRNA levels of cardiac fibrosis markers Col1a1 and Col3a1, and Mmp9 (Fig. 1e). MTT assay results revealed that the percentage of viable cardiac fibroblasts considerably increased after AngII treatment (Fig. 1f). Immunofluorescence analyses demonstrated that AngII treatment upregulated $\alpha$-SMA expression in cardiac fibroblasts in vitro (Fig. 1g). In agreement with the results obtained in vivo, Cav3

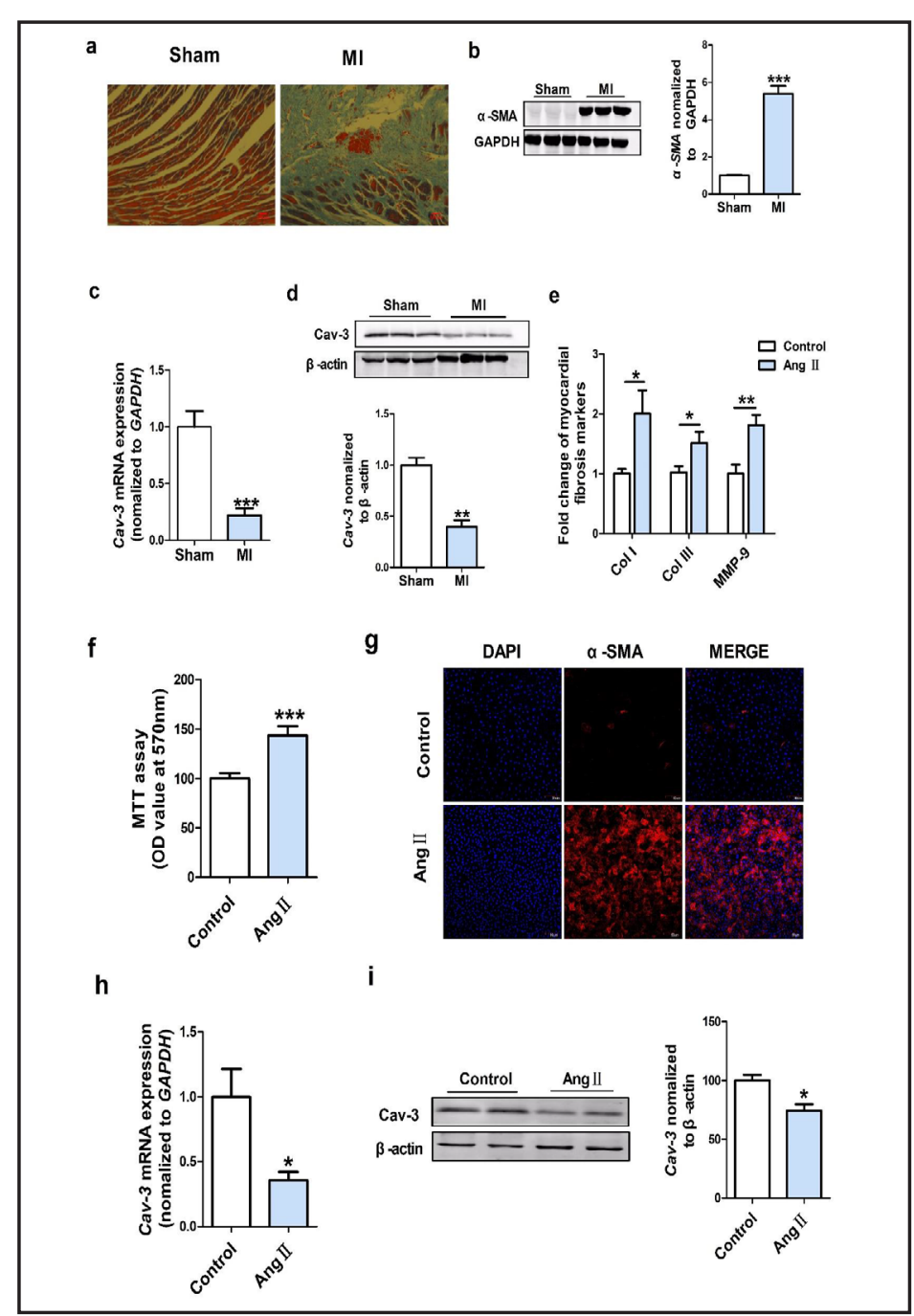

Fig. 1. Cav3 expression decreases in ischemic myocardia and in AngIItreated cardiac fibroblasts (CFs). a: Myocardial tissue section stained with Masson trichrome staining. Scale bars: $100 \mu \mathrm{m}$. b: Expression of $\alpha$-SMA; $\mathrm{n}=6$; ${ }^{* * *} \mathrm{P}<0.001$, compared with the Sham group. $\mathrm{c}, \mathrm{d}$ : Expression of Cav3 in MI at mRNA (c) and protein levels (d); $n=5$; *** $\mathrm{P}<0.001$, compared with the Sham group (mRNA expression); $\mathrm{n}=$ 6 ; ${ }^{* *} \mathrm{P}<0.01$ compared with the Sham group (protein expression). e: Collagen type I and III and Mmp9 expression; $\mathrm{n}=13$; ${ }^{*} \mathrm{P}<0.05,{ }^{* *} \mathrm{P}<0.01$, compared with the Control. f: CF proliferation rate; $\mathrm{n}=12$; ${ }^{* * *} \mathrm{P}<0.001$ compared with Control. g: $\alpha$-SMA expression in CFs. Scale bars: $5 \mu \mathrm{m}$. $\mathrm{h}$-i: Cav3 expression at mRNA (h) and protein (i) levels; $\mathrm{n}=6$; ${ }^{*} \mathrm{P}<0.05$ compared with Control (mRNA expression); $\mathrm{n}=15$; ${ }^{*} \mathrm{P}<0.05$ compared with the control (protein expression). 
levels were decreased at both mRNA (Fig. 1h) and protein levels (Fig. 1i) in the presence of AngII.

\section{Cav3 downregulation shows pro-fibrotic effects}

Furthermore, we examined the effects of Cav3 silencing on cardiac fibroblasts and the development of fibrosis. The data presented in Fig. 2a shows that the treatment with Cav3 small interfering (siRNA; siCav3) induced the increase in Col1a1 (2.5-fold, compared with the untreated control) and Col3a1 (2.1-fold) expression in cardiac fibroblasts, whereas the negative control construct (siNC) did not affect the expression of these genes. Moreover, Cav3 knockdown resulted in a $21 \%$ increase in cardiac fibroblast viability, compared with that of the cardiac fibroblasts transfected with siNC (Fig. 2b). The expression of $\alpha$-SMA was shown to be increased in cardiac fibroblasts treated with siCav3 (Fig. 2c). We confirmed that Cav3 expression was successfully silenced using quantitative reverse transcriptase-polymerase chain reaction (qRT-PCR; Fig. 2d).

To confirm our results further, we used gain-of-function approach, by constructing a plasmid harboring the Cav3 gene. As presented in Fig. 2e, cardiac fibroblasts transfected with Cav3-carrying plasmid were shown to have 1.8-fold higher Cav3 protein level than those transfected with the empty vector. Cav3 overexpression at $48 \mathrm{~h}$ mitigated AngIIinduced increasement in Col1a1 (by 43.1\%) and Col3a1 (by 26.2\%) expression (Fig. 2f). MTT assay results demonstrated that the overexpression of Cav3 reduced the viability of cardiac fibroblasts (Fig. 2g). Immunofluorescence analyses showed that the overexpression of Cav3

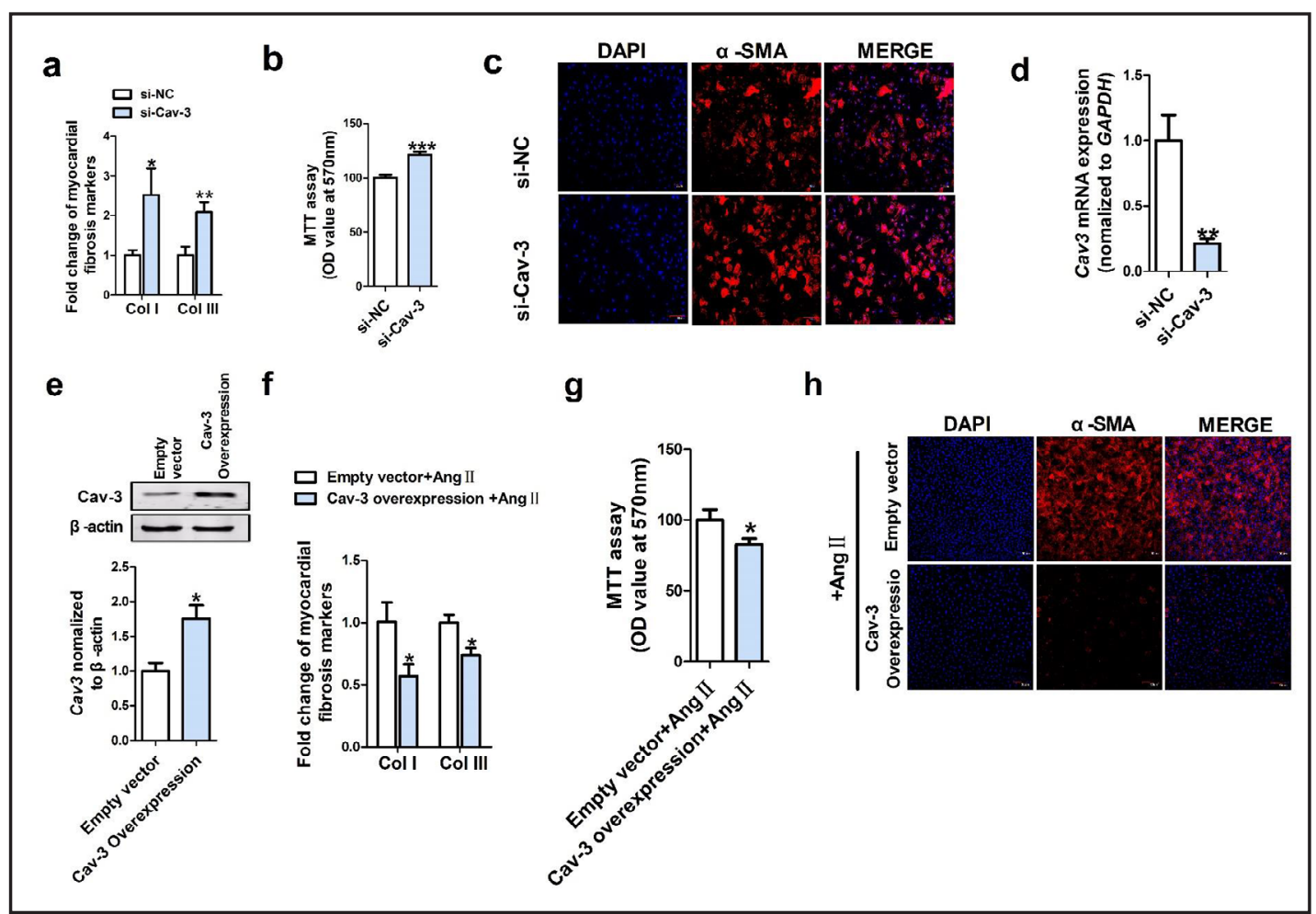

Fig. 2. Cav3 knockdown or overexpression effects on cardiac fibrosis. a: Col1a1/3a1 expression after siCav3 transfection; $\mathrm{n}=6$; ${ }^{*} \mathrm{P}<0.05,{ }^{* *} \mathrm{P}<0.01$ compared with si-NC. $\mathrm{b}$ : Cav3 silencing effects on cell viability; $\mathrm{n}=$ 20 ; ${ }^{* *} \mathrm{P}<0.001$ vs. si-NC. c: Fluorescence microscopy analysis of $\alpha$-SMA expression. Scale bars: $5 \mu \mathrm{m}$. d: Cav3 expression after its silencing in cardiac fibroblasts (CFs); $\mathrm{n}=8$; ${ }^{* *} \mathrm{P}<0.01$ vs. si-NC. e: Cav3 expression following the transfection of CFs with Cav3-overexpressing plasmid; $\mathrm{n}=7$; ${ }^{*} \mathrm{P}<0.05$ vs. Empty vector. f: Col1a1 and Col3a1 expression after $\mathrm{CF}$ transfection with Cav3-overexpressing plasmid; $\mathrm{n}=5 ;{ }^{*} \mathrm{P}<0.05$ vs. empty vector+AngII. g: Effects of Cav3 overexpression on CF proliferation; $n=15 ;{ }^{*} \mathrm{P}<0.05$ vs. empty vector+AngII. h: Effects of Cav3 overexpression on $\alpha$-SMA expression in CFs. Scale bars: $5 \mu \mathrm{m}$.

\section{KARGER}




\section{Cellular Physiology Cell Physiol Biochem 2018;45:1641-1653

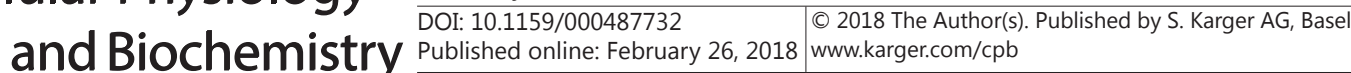 \\ Zhang et al.: Mir-22: A Cardiac Fibrosis Activator}

led to the inhibition of AngII-induced $\alpha$-SMA expression in cardiac fibroblasts (Fig. 2h).

\section{PKCE mediates Cav3 inhibition-induced development of fibrosis}

PKC is a family of protein kinases, which play critical roles in the regulation of cardiac functions and pathophysiological processes [50-52]. Here, we demonstrated that an activator of PKCE, FR236924, leads to an increase in Col1a1 and Col3a1 transcript levels by $58.1 \%$ and 98.6\%, respectively (Fig. 3a and 3b). Conversely, PKC $\varepsilon$ inhibitor peptide inhibited AngIIinduced upregulation of Col1a1 and Col3a1 expression by $58.2 \%$ and $78.6 \%$, respectively (Fig. 3a and 3b). Moreover, FR236924 was shown to promote cardiac fibroblast proliferation, while PKC $\varepsilon$ inhibitor peptide inhibited AngII-induced proliferation of these cells (Fig. 3c). As presented in Fig. 3d, $\alpha$-SMA expression was shown to be increased following the treatment of cardiac fibroblasts with FR236924, whereas AngII-induced $\alpha$-SMA upregulation in these cells decreased after PKC $\varepsilon$ inhibitor peptide treatment. Cav3 was reported to interact with several signaling proteins localized in the caveolae, such as PKC $\varepsilon, \delta$, and $\alpha$ [40-42]. Our western blot data (Fig. 3e) showed that the phosphorylation of PKC $\varepsilon$ at $\operatorname{Ser}^{729}$ (pPKC $\varepsilon$ ) increased after Cav3 silencing of in cardiac fibroblasts, while pPKCE levels decreased with the increase in Cav3 levels.

\section{miR-22 is a key regulator of Cav3 expression and function}

To determine the upstream regulators of the described processes, since miRNAs have recently been shown to participate in regulation of the expression of genes involved in cardiac fibrogenesis [53-55], we attempted to identify miRNAs that may target Cav3. TargetScan miRNA database analysis identified miR-22 as a candidate regulatory miRNA, since the 3'-UTR of the Cav3 gene contains two putative binding sites for miR-22 seed motif, which are highly conserved across the species, including rats, mice, and humans (Fig. 4a). We determined the expression levels of miR-22 in MI and Sham hearts, and our results demonstrated that miR-22 levels increased in the border zone in the MI mice and in the cardiac

Fig. 3. Cav3 overexpression inhibits AngII-induced fibrotic responses through PKC $\varepsilon$ dependent mechanism. a-b: Col1a1 (a) and Col3a1 (b) expression in cardiac fibroblasts (CFs) treated with FR236924, AngII or PKCE inhibitor peptide; $\mathrm{n}=5$; $* \mathrm{P}<0.05$ vs. Control. \#P<0.05 vs. AngII treated only. c: Effects of AngII, FR236924, or PKCE inhibitor peptide on CF proliferation;

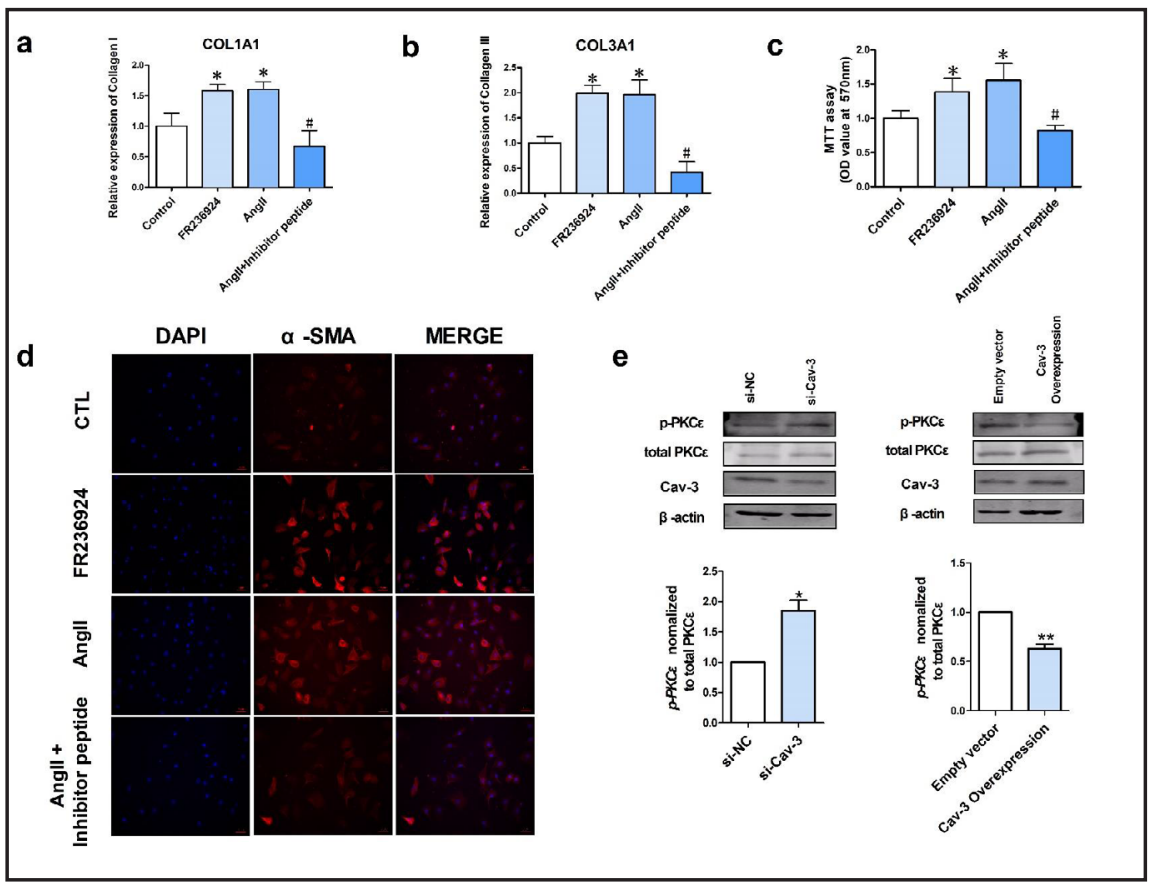
$\mathrm{n}=15 ;{ }^{*} \mathrm{P}<0.05$ vs.

Control. \#P<0.05 vs. AngII treated only. d: Effects of AngII, FR236924, or PKC $\varepsilon$ inhibitor peptide on $\alpha$-SMA expression in CFs. Scale bars: $5 \mu$ m. e: Effects of Cav3 on PKC $\varepsilon$ expression in CFs; $n=4 ;{ }^{*} \mathrm{P}<0.05$ vs. si-NC. $* * \mathrm{P}<0.01$ vs. Empty vector. 
fibroblasts treated with AngII, which was negatively correlated with Cav3 expression (Fig. 4b and $4 \mathrm{c}$ ). The transfection of miR22 mimic into cardiac fibroblasts decreased he mRNA and protein levels of Cav3 by nearly 33.2\% and $41.2 \%$, respectively, compared with those in the cells treated with the NC miRNA (Fig 4d and 4e), while these effects were inhibited by the co-transfection of cells with AMO22 (miR-22 antisense inhibitor). Furthermore, luciferase reporter gene assay was performed in order to validate Cav3 as a direct target of miR-22. We transfected the cells with the psiCHECK-2 vector carrying the wild-type (WT) or mutated sequences (MuT) found in the $3^{\prime}$-UTR of Cav3 (Cav3/3'-UTR) (Fig. 4f). As presented in Fig. 4g, the co-transfection of cells with miR-22 mimic substantially reduced (by $56.4 \%$ ) luciferase activity induced by the WT psiCHECK-2. The observed inhibition was decreased (by $27.7 \%$ ) when the vector carrying MuT at the nucleotide positions 236-243 in Cav3/3'UTR was used, while positioning the mutations at nucleotides 588594, miR-22 treatment reduced luciferase activity by $40.1 \%$, compared with that in the control. Using a double-mutation construct, we demonstrated that miR-22 lost the ability to affect luciferase activity (Fig. 4g). Successful delivery of miR-22 mimic and AMO22 into the cardiac fibroblasts was confirmed by qRT-PCR analysis (Fig. 4h).

Induced expression of miR-22 in cardiac fibroblasts considerably upregulated Col1a1 (2.4-fold) and Col3a1 (2.1-fold) expression levels, compared with those in the untreated cells (Fig. 5a), and led to an increase in the number of cardiac fibroblasts (Fig. 5b). In contrast to this, AMO-22 inhibited AngII-induced cardiac fibroblast proliferation (Fig. 5c). Immunofluorescence analysis showed that the overexpression of miR22 induced the expression of $\alpha$-SMA cardiac fibroblasts in vitro (Fig. 5d).

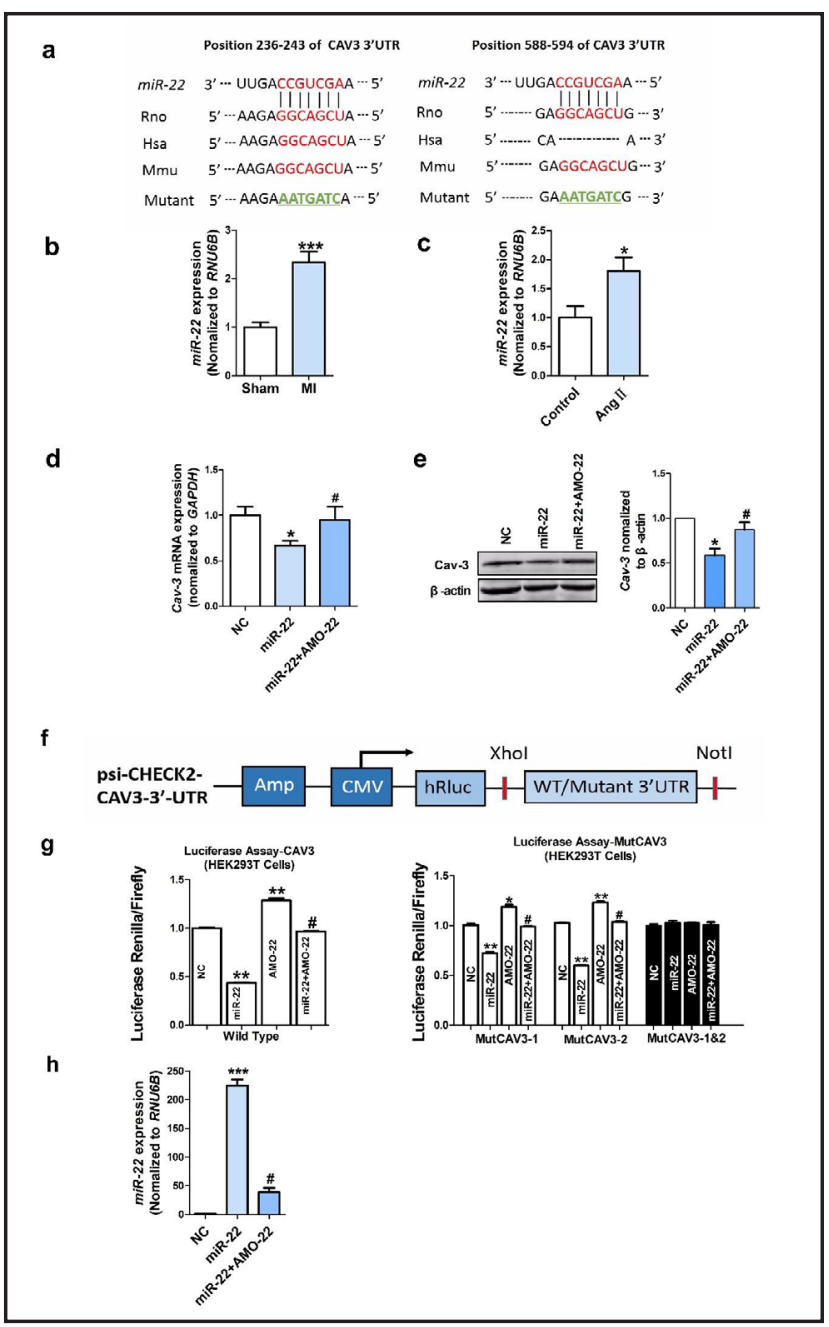

Fig. 4. Cav3 is a direct miR-22 target in cardiac fibroblasts (CFs). a: Complementarity between miR-22 and the two binding sites in the 3 '-UTR of Cav3 transcript. b: miR-22 levels after the normalization to RNU6B levels, in the infarct border zone; $\mathrm{n}=5$; ${ }^{* * *} \mathrm{P}<0.001$ vs. Sham. c: miR-22 expression in CFs treated with AngII; $\mathrm{n}=8 ;{ }^{*} \mathrm{P}<0.05$ vs. Control. d: Transfection efficiency of miR-22; $\mathrm{n}=4 ;{ }^{*} \mathrm{P}<0.05$ vs. NC. \#P<0.05 vs. miR-22. e: Effects of miR-22 treatment on Cav3 expression in CFs; $\mathrm{n}=3 ;{ }^{*} \mathrm{P}<0.05$ vs. $\mathrm{NC}, \# \mathrm{P}<0.05$ vs. miR-22. f: Schematic diagram of the psiCHECK-2 vector, showing the cloning sites of the wild-type (WT) or mutant sequences in the $3^{\prime}$-UTR of the luciferase gene. g: Luciferase reporter gene assay, demonstrating the inhibition of Cav3 expression by miR-22 in HEK293T cells; $\mathrm{n}=3$; ${ }^{*} \mathrm{P}<0.05 ;{ }^{*} \mathrm{P}<0.01$ vs. $\mathrm{NC}$. $\# \mathrm{P}<0.05$ vs. miR-22. $\mathrm{H}$ : verify the efficiency of miR-22 and AMO-22; ${ }^{* * *} \mathrm{P}<0.001$ vs. NC, ${ }^{\#} \mathrm{P}<0.05$ vs. miR-22. 
Fig. 5. miR-22 overexpression induces collagen deposition, cardiac fibroblast (CF) proliferation, and $\alpha$-SMA expression. a: MiR-22 effects on Col1a1 and Col3a1 expression; $\mathrm{n}=5$; ${ }^{*} \mathrm{P}<0.05$ vs. NC. $\mathrm{b}$ : MiR-22 expression effects on $\mathrm{CF}$ proliferation; $\mathrm{n}=15$; ${ }^{* * *} \mathrm{P}<0.001$ vs NC. c: Effect of AMO-22 treatment on Ang II-induced CF proliferation; $\mathrm{n}=15 ;{ }^{* * *} \mathrm{P}<0.001$ vs. $\mathrm{NCi}+$ Ang II . d: Effects of miR-22 expression on $\alpha$-SMA levels in CFs. Scale bars: 5 $\mu \mathrm{m}$.

\section{Discussion}

To the best of our knowledge, here we presented for the first time the anti-fibrotic properties of Cav3, showing that Cav3 levels are considerably decreased in a mouse model of MI and in AngII-treated cardiac fibroblasts in vitro. Cav3 downregulation was shown to promote cardiac fibrosis induced by MI or AngII. This induced the phosphorylation of PKC $\varepsilon$, which in turn led to the development of cardiac fibrosis. Furthermore, we demonstrated that miR-22 was markedly upregulated after MI and in the AngII-treated cardiac fibroblasts, which was shown to lead, at least partially, to the downregulation of Cav3, demonstrating that Cav3 represents a direct target of miR-22. Additionally, miR-22 overexpression was shown to induce cardiac fibrosis rate. Therefore, we showed a novel molecular mechanism underlying cardiac fibrosis and elucidated the role of miR-22/Cav3/pPKCe signaling in cardiac fibrosis (Fig 6).

Cav3 is the main component of caveolae in cardiac cells, and it was shown to play an important role in maintaining cardiac function [56] and intracellular calcium homeostasis [57]. Furthermore, its dysregulation is involved in the development of arrhythmia, myocardial hypertrophy, and myocardial ischemia/reperfusion injury [17-19]. However, no previous studies elucidated the regulatory role of Cav3 during the development of cardiac fibrosis. In this study, we showed that Cav3 silencing induces the proliferation and differentiation of cardiac fibroblasts into myofibroblasts, and the accumulation of collagen. However, Cav3 overexpression may rescue AngII-induced pathological myofibroblast formation, indicated by $\alpha$-SMA expression alterations, proliferation, indicated by the changes in the cardiac fibroblast number, and collagen deposition. Therefore, our findings show that Cav3 may represent an anti-fibrotic factor. The changes in the relationships between Cav3 and its interacting partners may contribute to the development of several cardiac pathological conditions. For example, the stabilization Cav3/LG-EMMPRIN complex plays a significant role in the cardioprotective effects of Nitric oxide against ischemia-reperfusion [58]. Hypoxic preconditioning promotes rapid association of $\mathrm{PKC} \varepsilon, \mathrm{PKC} \delta$, and $\mathrm{PKC} \alpha$ with the Cav-enriched plasma membrane microdomain of cardiac myocytes, and PKC $\varepsilon$ via a direct molecular interaction with Cav3 [26]. PKCE is essential for the adhesion and migration of cells [59], and the lack of PKCE results in an increased collagen deposition and impaired diastolic function [60]. Inagaki et al. [61] showed that the increase in PKCE expression promotes the proliferation of cardiac fibroblasts and induces cardiac fibrosis. Here, we demonstrated that collagen deposition and cardiac fibroblasts proliferation increased with PKC $\varepsilon$ activation and decreased upon PKC $\mathrm{P}$ inhibition. PKC $\varepsilon$ phosphorylation was shown to increase following the silencing of Cav3, while this phosphorylation decreased after Cav3 overexpression.

The data obtained here indicate that the upregulation of miR-22 is responsible, at least partially, for the downregulation of Cav3 during cardiac fibrosis development. miR-22 over- 
expression inhibited Cav3 expression at both mRNA and protein levels. Additionally, using the luciferase activity assay, we demonstrated the direct interaction between miR22 and the 3'-UTR of the Cav3 gene. Interestingly, the upregulation of miR-22 or downregulation of Cav3 alone induced cardiac fibrosis.

Our most important innovation is to find the loss of Cav3 could aggravate cardiac fibro-

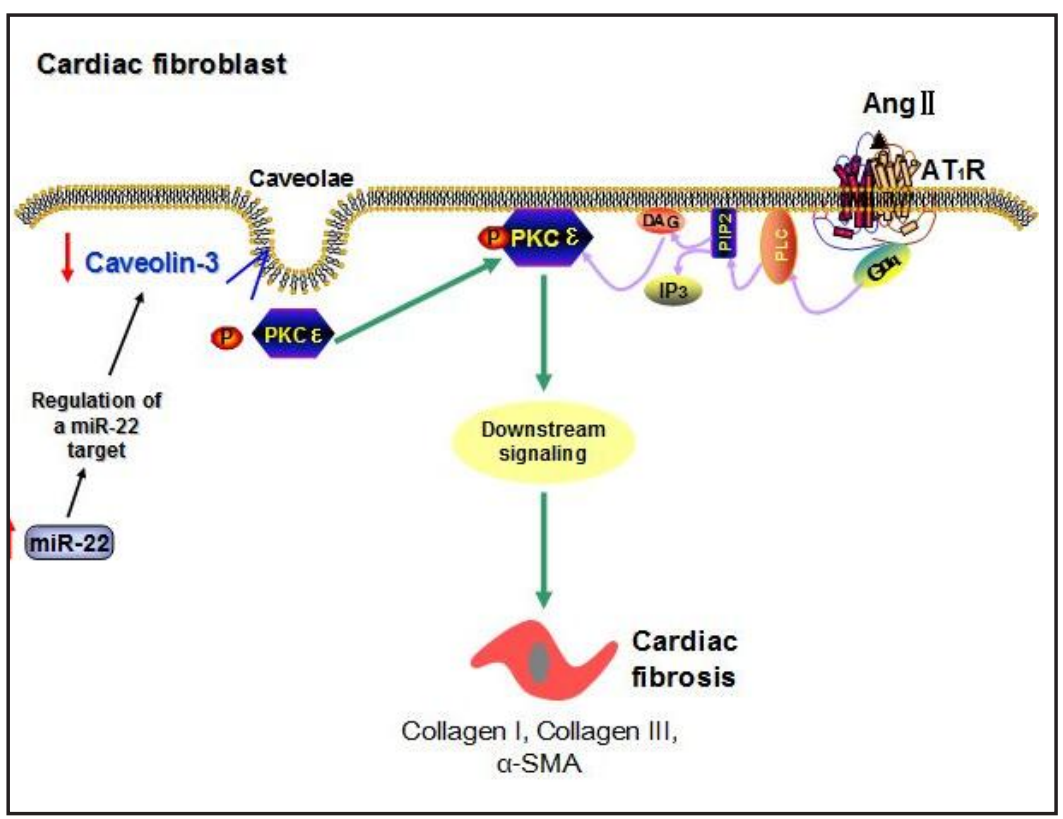

Fig. 6. The specific mechanism of Caveolin-3-mediated cardiac fibrosis. sis. Meanwhile, we found the level of cardiac fibrosis is relieved when transfected Cav3 expression plasmid, which may provide a new biomarker or therapeutic target against cardiac fibrosis for us.

On this basis, our second innovation is to clarify the mechanism of Cav3 regulating cardiac fibrosis, and answered the question why Cav3 changed and how Cav3 worked in cardiac fibrosis. Here we reported that Cav3 regulates cardiac fibrosis by regulating phosphorylation of PKCE, and miR-22 could inhibit the expression of Cav3, which provides us with new targets and new ideas for the treatment of cardiac fibrosis in the future.

\section{Acknowledgements}

This work was supported in part by the National Nature Science Foundation of China (No. 81470490, No. 81670238 and No. 81570301).

YZ, HLS and BFY designed, performed the research and supervised all aspects of the study and analysis. LZ, HLY, TYL, YQG and YYZ performed study and analysis the data. LJ, YCS and HLS assisted in this study. YZ, HLY and BFY finalized the manuscript. LZ and LJ supervised the research.

\section{Disclosure Statement}

The authors declare no conflicts of interest concerning this article.

\section{References}

\footnotetext{
1 Krenning G, Zeisberg EM and Kalluri R: The origin of fibroblasts and mechanism of cardiac fibrosis. J Cell Physiol 2010;225:631-637.

-2 Lai CH, Han CK, Shibu MA, Pai PY, Ho TJ, Day CH, Tsai FJ, Tsai CH, Yao CH, Huang CY: Lumbrokinase from earthworm extract ameliorates second-hand smoke-induced cardiac fibrosis. Environ Toxicol 2014;30:1216-1225.
} 


\section{Cellular Physiology Cell Physiol Biochem 2018;45:1641-1653 \begin{tabular}{ll|l|l|l|l} 
DOI: 10.1159/000487732 2018 The Author(s). Published by S. Karger AG, Basel & and Biochemistry \\
Published online: February 26, 2018 & www.karger.com/cpb
\end{tabular}

3 Brown RD, Ambler SK, Mitchell MD, Long CS: The cardiac fibroblast: Therapeutic target in myocardial remodeling and failure. Annu Rev Pharmacol 2005;45:657-687.

-4 Dean RG, Balding LC, Candido R, Burns WC, Cao Z, Twigg SM, Burrell LM: Connective tissue growth factor and cardiac fibrosis after myocardial infarction. J Histochem Cytochem 2005;53:1245-1256.

5 Jong GP, Ma T, Chou P, Chang MH, Wu CH, Lis PC, Lee SD, Liu JY, Kuo WW, Huang CY: Serum mmp-9 activity as a diagnosing marker for the developing heart failure of post mi patients. Chin J Physiol 2006;49:104109.

6 Pitt B, Remme W, Zannad F, Neaton J, Martinez F, Roniker B, Bittman R, Hurley S, Kleiman J and Gatlin M: Eplerenone, a selective aldosterone blocker, in patients with left ventricular dysfunction after myocardial infarction. N Engl J Med. 2003;348:1309-1321.

7 Brilla CG, Zhou G, Matsubara L, Weber KT: Collagen metabolism in cultured adult rat cardiac fibroblasts: Response to angiotensin ii and aldosterone. J Mol Cell Cardiol 1994;26:809-820. Rosenkranz S: Tgf- $\beta 1$ and angiotensin networking in cardiac remodeling. Cardiovasc Res 2004;63:423-432. Porter KE, Turner NA: Cardiac fibroblasts: At the heart of myocardial remodeling. Pharmacol Ther 2009;123:255-278.

10 Khan R, Sheppard R: Fibrosis in heart disease: Understanding the role of transforming growth factor- $\beta 1$ in cardiomyopathy, valvular disease and arrhythmia. Immunology 2006;118:10-24.

11 Anderson KR, Sutton MGSJ, Lie JT: Histopathological types of cardiac fibrosis in myocardial disease. J Pathol 1979;128:79-85.

12 Anderson RG: The caveolae membrane system. Annu Rev Biochem 1998;67:199-225.

13 Cohen AW, Hnasko R, Schubert W, Lisanti MP: Role of caveolae and caveolins in health and disease. Physiol Rev 2004;84:1341-1379.

14 Rothberg KG, Heuser JE, Donzell WC, Ying YS, Glenney JR, Anderson RG: Caveolin, a protein component of caveolae membrane coats. Cell 1992;68:673-682.

15 Williams TM, Lisanti MP: The caveolin proteins. Genome Biol 2004;5:60-60.

16 Song KS, Scherer PE, Tang Z, Okamoto T, Li S, Chafel M, Chu C, Kohtz DS, Lisanti MP: Expression of caveolin-3 in skeletal, cardiac, and smooth muscle cells. Caveolin-3 is a component of the sarcolemma and co-fractionates with dystrophin and dystrophin-associated glycoproteins. J Biol Chem 1996;271:1516015165.

17 Woodman SE, Park DS, Cohen AW, Cheung MW, Chandra M, Shirani J, Tang B, Jelicks LA, Kitsis RN, Christ GJ: Caveolin-3 knock-out mice develop a progressive cardiomyopathy and show hyperactivation of the p42/44 mapk cascade. J Biol Chem 2002;277:38988-38997.

18 Markandeya YS, Phelan LJ, Woon MT, Keefe AM, Reynolds CR, August BK, Hacker TA, Roth DM, Patel HH and Balijepalli RC: Caveolin-3 overexpression attenuates cardiac hypertrophy via inhibition of T-type $\mathrm{Ca}^{2+}$ current modulated by protein kinase calpha in cardiomyocytes. J Biol Chem 2015;290:22085-220100.

19 Zhao J, Wang F, Zhang Y, Jiao L, Lau WB, Wang L, Liu B, Gao E, Koch WJ, Ma XL: Sevoflurane preconditioning attenuates myocardial ischemia/reperfusion injury via caveolin-3-dependent cyclooxygenase-2 inhibition. Circulation 2013;128:121-129.

-20 Li Z, Abdullah CS, Jin ZQ: Inhibition of pkc- $\theta$ preserves cardiac function and reduces fibrosis in streptozotocin-induced diabetic cardiomyopathy. Br J Pharmacol 2014;171:2913-2924.

-21 Xiang S, Qian X, Ming S, Rong J, Wagner MB, Ding G, Chen G, Shen B: Protein kinase c promotes cardiac fibrosis and heart failure by modulating galectin-3 expression. Biochim Biophys Acta 2015;1853:513-521.

22 Inagaki K, Koyanagi T, Berry NC, Sun L, Mochlyrosen D: Pharmacological inhibition of epsilon-protein kinase $\mathrm{c}$ attenuates cardiac fibrosis and dysfunction in hypertension-induced heart failure. Hypertension 2008;51:1565-1569.

23 Nishizuka Y: Studies and perspectives of pkc. Science 1986;233:305-312.

-24 VivekGarg, JundongJiao, KeliHu: Regulation of atp-sensitive $\mathrm{k}^{+}$channels by caveolin-enriched microdomains in cardiac myocytes. Cardiovasc Res 2009;82:51-58.

25 Yu H, Yang Z, Pan S, Yang Y, Tian J, Wang L, Sun W: Hypoxic preconditioning promotes the translocation of protein kinase c $\varepsilon$ binding with caveolin-3 at cell membrane not mitochondrial in rat heart. Cell Cycle 2015;14:3557-3565.

26 Liu Y, Jin J, Li H, Huang H, Irwin MG, Xia Z: Inhibition of pkc $\beta 2$ attenuates myocardial ischemia reperfusion injury in diabetic rat through cavolin-3-dependant akt activation. Circulation 2014;130:A18247-A18247. 


\section{Cellular Physiology Cell Physiol Biochem 2018;45:1641-1653 \begin{tabular}{ll|l|l|l|l} 
DOI: 10.1159/000487732 2018 The Author(s). Published by S. Karger AG, Basel & and Biochemistry \\
Published online: February 26, 2018 & www.karger.com/cpb
\end{tabular}}

Zhang et al.: Mir-22: A Cardiac Fibrosis Activator

-27 Liu Y, Jin J, Qiao S, Lei S, Liao S, Ge ZD, Li H, Wong GT, Irwin MG, Xia Z: Inhibition of pkc $\beta 2$ overexpression ameliorates myocardial ischaemia/reperfusion injury in diabetic rats via restoring caveolin-3/akt signaling. CLIN SCI 2015;129:331-344.

28 Bauersachs J, Thum T: Biogenesis and regulation of cardiovascular microRNAs. Circ Res 2011;109:334-347.

-29 Berezikov E, Guryev V, Van dBJ, Wienholds E, Plasterk RH, Cuppen E: Phylogenetic shadowing and computational identification of human microRNA genes. Cell 2005;120:21-24.

30 Xie X, Lu J, Kulbokas EJ, Golub TR, Mootha V, Lindblad-Toh K, Lander ES, Kellis M: Systematic discovery of regulatory motifs in human promoters and 3' utrs by comparison of several mammals. Nature 2005;434:338-345.

-31 Liao XB, Perez VA, Król M, Yeh CH, Yuan LQ: MicroRNA and cardiovascular disease. Biomed Res Int. 2015;2015:734380.

-32 Nattel S, Harada M: Atrial remodeling and atrial fibrillation: Recent advances and translational perspectives. J Am Coll Cardiol 2014;63:2335-2345.

-33 Da CMP, Bourajjaj M, Gladka M, Kortland M, van Oort RJ, Pinto YM, Molkentin JD, De Windt LJ: Conditional dicer gene deletion in the postnatal myocardium provokes spontaneous cardiac remodeling. Circulation 2008;118:1567-1576.

-34 Wang J, Huang W, Xu R, Nie Y, Cao X, Meng J, Xu X, Hu S, Zheng Z: MicroRNA-24 regulates cardiac fibrosis after myocardial infarction. J Cell Mol Med 2012;16:2150-2160.

-35 Zhu JN, Chen R, Fu YH, Lin QX, Huang S, Guo LL, Zhang MZ, Deng CY, Zou X, Zhong SL: Smad3 inactivation and mir-29b upregulation mediate the effect of carvedilol on attenuating the acute myocardium infarctioninduced myocardial fibrosis in rat. PLoS One 2013;8:e75557-e75557.

-36 Zhang Y, Huang XR, Wei LH, Chung AC, Yu CM, Lan HY: MiRNA-29b as a therapeutic agent for angiotensin ii-induced cardiac fibrosis by targeting TGFb/smad3 signaling. Mol Ther 2014;22:974-985.

-37 Duisters RF, Tijsen AJ, Schroen B, Leenders JJ, Lentink V, Made IVD, Herias V, Leeuwen REV, Schellings MW, Barenbrug P: Mir-133 and mir-30 regulate connective tissue growth factor implications for a role of microRNAs in myocardial matrix remodeling. Circ Res 2009;104:170-178.

-38 Shan H, Zhang Y, Lu Y, Zhang Y, Pan Z, Cai B, Wang N, Li X, Feng T, Hong Y: Downregulation of mir-133 and mir-590 contributes to nicotine-induced atrial remodelling in canines. Cardiovasc Res 2009;83:465-472.

-39 Liu N, Bezprozvannaya S, Williams AH, Qi X, Richardson JA, Basselduby R, Olson EN: MicroRNA-133a regulates cardiomyocyte proliferation and suppresses smooth muscle gene expression in the heart. Genes Dev 2008;22:3242-3254.

40 Dawson K, Wakili R, Ordög B, Clauss S, Chen Y, Iwasaki Y, Voigt N, Qi XY, Sinner MF, Dobrev D: MicroRNA-29: A mechanistic contributor and potential biomarker in atrial fibrillation. Circulation 2013;127:1466-1475, 1475e1-28.

41 Guo C, Deng Y, Liu J, Qian L: Cardiomyocyte-specific role of miRNA-24 in promoting cell survival. J Cellular Mol Med 2015;19:103-112.

42 Roncarati R, Anselmi CV, Losi MA, Papa L, Cavarretta E, Martins PDC, Contaldi C, Jotti GS, Franzone A, Galastri L: Circulating mir-29a, among other up-regulated microRNAs, is the only biomarker for both hypertrophy and fibrosis in patients with hypertrophic cardiomyopathy. J. Am. Coll. Cardiol 2014;63:920927.

43 Adam 0, Löhfelm B, Thum T, Gupta SK: Role of mir-21 in the pathogenesis of atrial fibrosis. Basic Res Cardiol 2012;107:278.

44 Roy S, Khanna S, Hussain SR, Biswas S, Azad A, Rink C, Gnyawali S, Shilo S, Nuovo GJ, Sen CK: Editor's choice: MicroRNA expression in response to murine myocardial infarction: Mir-21 regulates fibroblast metalloprotease-2 via phosphatase and tensin homologue. Cardiovasc Res 2009;82:21-29.

45 Rooij EV, Olson EN: Control of stress-dependent cardiac growth and gene expression by a microRNA. Science 2007;316:575-579.

46 Satoh M, Minami Y, Takahashi Y, Tabuchi T, Nakamura M: Expression of microRNA-208 is associated with adverse clinical outcomes in human dilated cardiomyopathy. J Card Fail 2010;16:404-410.

47 Wang BW, Wu GJ, Cheng WP, Shyu KG: MicroRNA-208a increases myocardial fibrosis via endoglin in volume overloading heart. PLoS One 2014;9:e84188.

48 Liang H, Zhang C, Ban T, Liu Y, Mei L, Piao X, Zhao D, Lu Y, Chu W, Yang B: A novel reciprocal loop between microRNA-21 and tgf $\beta$ RIII is involved in cardiac fibrosis. Int J Biochem Cell Biol 2012;44:2152-2160. 


\section{Cellular Physiology Cell Physiol Biochem 2018;45:1641-1653 \begin{tabular}{ll|l|l|l} 
DOI: 10.1159/000487732 & 2018 The Author(s). Published by S. Karger AG, Basel \\
and Biochemistry & Published online: February 26, 2018 www.karger.com/cpb
\end{tabular}}

Zhang et al.: Mir-22: A Cardiac Fibrosis Activator

49 Mitchell MD, Laird RE, Brown RD, Long CS: IL-1beta stimulates rat cardiac fibroblast migration via map kinase pathways. Am J Physiol Heart Circ Physiol 2007;292:H1139-H1147.

-50 Braz JC, Gregory K, Pathak A, Zhao W, Sahin B, Klevitsky R, Kimball TF, Lorenz JN, Nairn AC, Liggett SB: Pkcalpha regulates cardiac contractility and propensity toward heart failure. Nat Med 2004;10:248.

51 Mayr M, Metzler B, Chung YL, Mcgregor E, Mayr U, Troy H, Hu Y, Leitges M, Pachinger O, Griffiths JR: Ischemic preconditioning exaggerates cardiac damage in pkc- $\delta$ null mice. Am J Physiol Heart Circ Physiol 2004;287:H946-H956.

-52 Murriel CL, Mochly-Rosen D: Opposing roles of delta and epsilonpkc in cardiac ischemia and reperfusion: Targeting the apoptotic machinery. Arch Biochem Biophys 2003;420:246-254.

-53 Nagpal V, Rai R, Place AT, Murphy SB, Verma SK, Ghosh AK, Vaughan DE: Mir-125b is critical for fibroblastto-myofibroblast transition and cardiac fibrosis. Circulation 2016;133:291-301.

54 Wang J, Huang W, Xu R, Nie Y, Cao X, Meng J, Xu X, Hu S, Zheng Z: MicroRNA-24 regulates cardiac fibrosis after myocardial infarction. J Cell Mol Med 2012;16:2150-2160.

55 Pan Z, Sun X, Shan H, Wang N, Wang J, Ren J, Feng S, Xie L, Lu C, Ye Y: MicroRNA-101 inhibited postinfarct cardiac fibrosis and improved left ventricular compliance via the FBJ osteosarcoma oncogene/ transforming growth factor- $\beta 1$ pathway. Circulation 2012;126:840-850.

56 Li H, Yao W, Liu Z, Xu A, Huang Y, Ma XL, Irwin MG and Xia Z: Hyperglycemia abrogates ischemic postconditioning cardioprotection by impairing AdipoR1/Caveolin-3/STAT3 signaling in diabetic rats. Diabetes 2016;65:942-955.

57 Whiteley G, Collins RF and Kitmitto A: Characterization of the molecular architecture of human caveolin-3 and interaction with the skeletal muscle ryanodine receptor. J Biol Chem 2012;287:40302-40316.

-58 Cuadrado I, Castejon B, Martin AM, Saura M, Reventuntorralba P, Zamorano JL, Zaragoza C: Nitric oxide induces cardiac protection by preventing extracellular matrix degradation through the complex caveolin-3/ emmprin in cardiac myocytes. PLoS One 2016;11:e0162912.

59 Besson A, Davy A, Robbins SM, Yong VW: Differential activation of erks to focal adhesions by pkc epsilon is required for pma-induced adhesion and migration of human glioma cells. Oncogene 2001;20:7398-7407.

60 Klein G, Schaefer A, Hilfikerkleiner D, Oppermann D, Shukla P, Quint A, Podewski E, Hilfiker A, Schröder F, Leitges M: Increased collagen deposition and diastolic dysfunction but preserved myocardial hypertrophy after pressure overload in mice lacking pkcepsilon. Circ Res 2005;96:748-755.

61 Inagaki K, Koyanagi T, Berry NC, Sun L, Mochlyrosen D: Pharmacological inhibition of $\varepsilon$-protein kinase $\mathrm{c}$ attenuates cardiac fibrosis and dysfunction in hypertension-induced heart failure. Hypertension 2008;51:1565-1569. 